\title{
Energy Storage for the Australian National Electricity Market Grid
}

\author{
Wael Al-Kouz ${ }^{1, *}$, Jamal Nayfeh, and Alberto Boretti ${ }^{1}$ \\ ${ }^{1}$ Mechanical Engineering Department, Prince Mohammad Bin Fahd University, Al-Khobar, Kingdom of Saudi Arabia
}

\begin{abstract}
The paper discusses the energy storage needs for the Australian National Electricity Market grid, based on the analysis of the power generation, wind and solar energy facilities and solar rooftop, and the grid demand. It is concluded that significant energy storage, for both powers of storing or delivering energy, and time this power can be stored or released, is needed. While pumped hydro energy storage from retrofitting of existing hydroelectric facilities may certainly provide a rapid short term growth of energy storage, additional expansions are difficult, and battery storage, that is challenging for sustainability, economic and environmental issues, must be considered.
\end{abstract}

\section{Introduction}

The achievable share of total primary energy supply (TPES) by wind and solar is limited by their intermittency and unpredictability. The TPES by source, World 1990-2017 from [1] tells us that worldwide, the energy production solar and wind, plus the negligible geothermal, tide, wave, and the ocean, is still about only $1.8 \%$ of the global TPES. Despite the increasing capacities of wind and solar, their contribution to the actual electricity production, without energy storage, is thus increasing less than the capacity, and it is still small. This is because of the unresolved, very marginally tackled energy storage issue [2], [3].

The rapidly increasing capacity (nominal generating power of wind and solar facilities) [4] is not the best indicator of the contribution by wind and solar to the TPES or the generation of electricity. The nominal generating capacity is not a correct measure of the actual electricity produced by wind and solar, because wind and solar are intermittent and unpredictable and do not work often about their registered capacity [2], [3]. The annual capacity factors of wind or solar photovoltaic (PV) energy facilities are about 0.33-0.35, or 0.27-0.29 respectively. Distributed solar PV rooftops have much smaller capacity factors, at about $15 \%$ and less. Conventional plants must compensate for the production of solar and wind below their nominal capacity. Solar energy without storage needs fossil fuel combustion to produce the missing solar output during the night time or during covered days. Similarly, when the production of wind energy facilities falls below the peaks, down to the valleys, fossil fuel combustion must replace their missing production. If we do not want to waste any renewable energy electricity produced by wind and solar, without having energy storage, the nominal capacity by wind and solar has to be matched by fossil fuel combustion power plants. The share by wind and solar of the total electricity production to a balanced grid is thus inevitably much less than $50 \%$.

\section{A grid wind and solar only}

The intermittency and unpredictability of both solar and wind is the major challenge of a renewable energy only economy, not only electricity grid but TPES, including electric-only mobility. For what concerns the electricity grid, that is the first step, here we consider as a sample case study the Australian National Electricity Market Grid (NEM). Even when the sum of all the solar and wind energy facilities connected to a same, whatever large, grid is considered, for example, the more than $5,000 \mathrm{~km}$ long Australian NEM Grid, that covers the states of South Australia, Victoria, Tasmania, New South Wales, and Queensland, the variability of solar and wind is still huge [2], [3].

As shown in [5], without considering the generation by solar PV rooftop systems, in the fiscal year 2016/17 the annual generation by fuel type was $77 \%$ coal, $9 \%$ gas, $8 \%$ hydro, $5 \%$ wind, $0.3 \%$ solar, and $0.7 \%$ other, Fig. 1 . This is very far from what could be expected by the large increments of wind and solar capacity highlighted by [4]. The latest registered capacity of solar energy facilities is $3,427 \mathrm{MW}$, while the latest registered capacity of wind Energy facilities is 6,702 MW. The latest registered capacity of the solar rooftop is likely in excess of 8,000 MW [6]. The total generating capacity mentioned in [5] for all the facilities in the grid is 54,421 MW, including everything, solar rooftop included. The grid always demands less than about $36 \mathrm{GW}$ of power.

Solar PV is available, on an annual average, only 12 hours per day, with also variation day-to-day and monthto-month. The annual average capacity factor is about $0.27-0.29$, but there are daily oscillations from 0 to

Corresponding author: walkouz@pmu.edu.sa 
something approaching 1, depending on the weather and season. Hence, solar alone cannot help with the coverage of energy needs without energy storage.

Things are marginally better with the wind, that is available $24 / 7$, but with instantaneous average capacity factors ranging from minimums of about 0.05 to maximums of about 0.65 , also changing with the season, and annual average capacity factors about $0.33-0.35$. Without energy storage, if one of the lows occurs during night-time, then this $5 \%$ of the nominal capacity must meet the entire demand for electricity from the grid. That is clearly a significant demand.

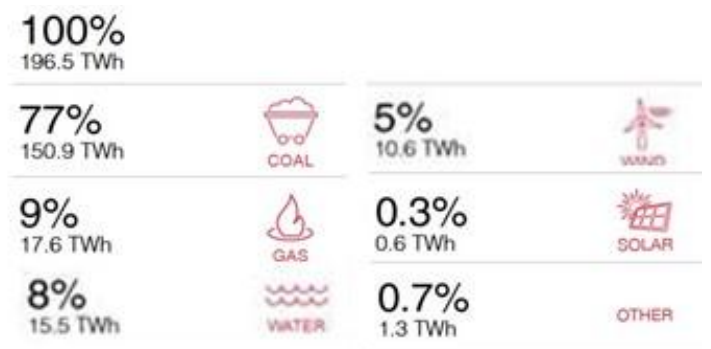

Fig. 1. Annual generation by fuel type 2016/2017 in the NEM grid. Data does not include generation from rooftop solar PV systems. Image reproduced modified from [5].

While more wind energy facilities spread out over a larger area may possibly smooth out peaks and valleys, this smoothing is however limited as some correlation still exists. Furthermore, as soon as the best sites for wind will be saturated, then additional wind energy facilities will have even more difficulties in delivering the high capacity factors of today's facilities. Finally, the peaks and valleys down to $5 \%$ and up to $65 \%$ of the nominal capacity are the results of a statistic with relatively large sampling times (3 hours' average). Things may be much worse with resolutions below 1minute intervals as it is necessary to stabilize a grid.

As shown in [7] and [8] by analyzing the power data of wind and solar PV energy facilities over a full year with a 5 minutes sampling frequency, while the average capacity factors are $0.27-0.38$, their standard deviations have about same values, for coefficients of variations about unity. This indicates the extreme variability of the individual sources of renewable energy, that makes it hard to provide about constant outputs even with significant space averaging. Fig. 2, 3 and 4 present the grid demand and the supply of solar and wind power over one sample day and one sample month. The monthly graphs have a frequency of 3-hours.

The daily graphs have a frequency of 5-minutes. Rooftop solar does not feature in the AEMO dispatchable (SCADA) data used for the rest of the sources. This data is merged for display in [9], in order to create a more complete representation of the supply to the grid.

There is a sort of correlation existing between solar production and peak demand during the day, that is interesting, but it does not address the variability issue. Peaks and valleys of demand and wind or solar are not correlated very well. By expanding the capacity of wind and solar by whatever the multiplication factor, without energy storage, solar is ineffective, while wind must have nominal capacities of about 20 times the maximum power requested in any months over one year.

Without energy storage, to cover all the grid demand it would be necessary a huge wind energy potential with up to $95 \%$ of this potential wasted if no other use is considered, and the $100 \%$ of the solar potential wasted if no other use is considered.

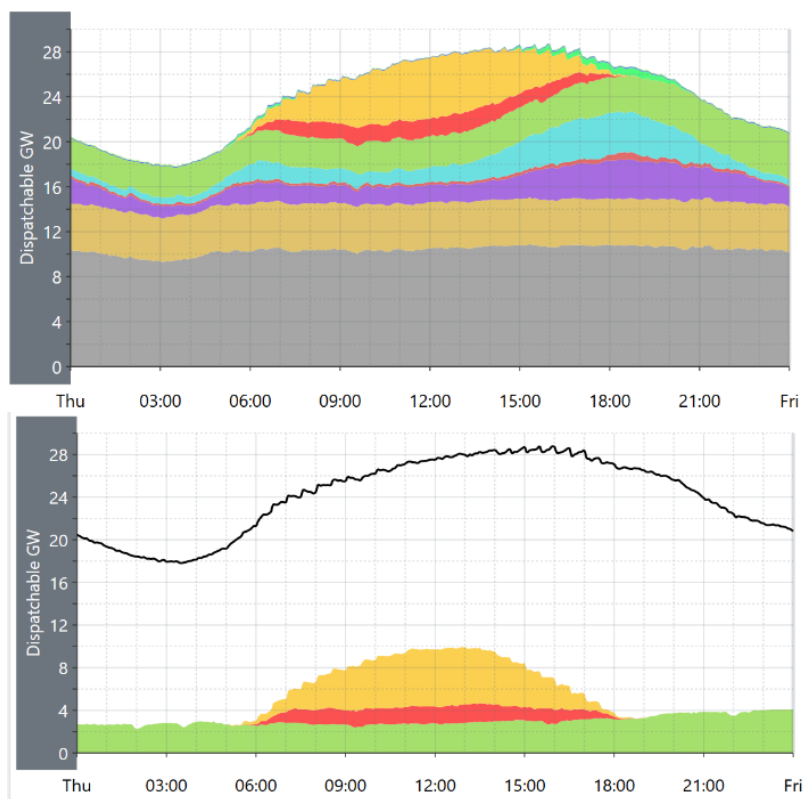

Fig. 2. Total NEM grid demand, and wind and solar facilities and solar rooftop power supply over one sample day, October 31,2019 . Images reproduced modified from [9].
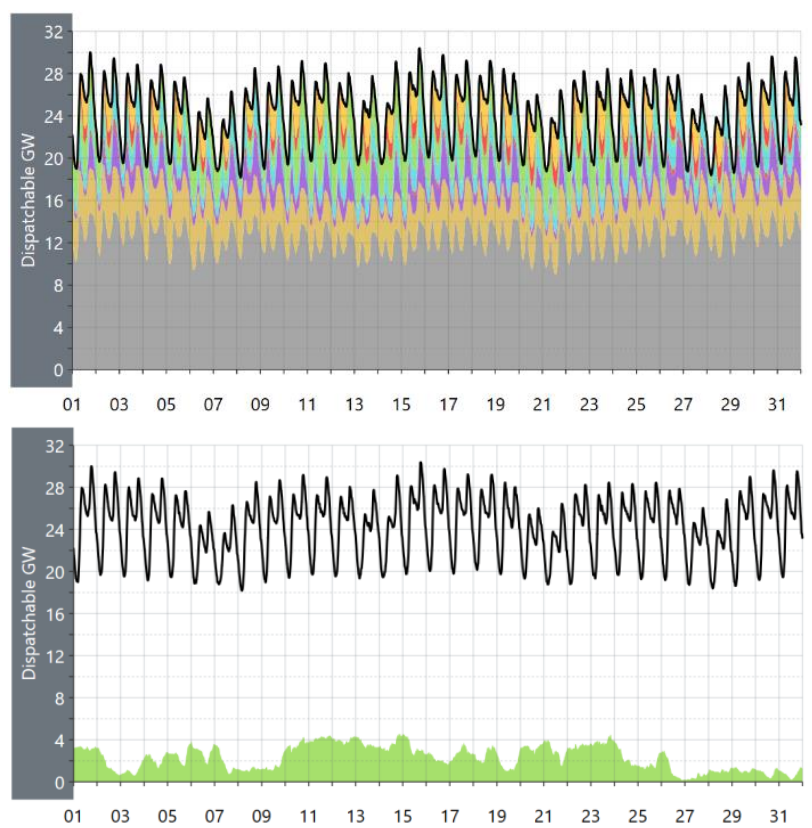

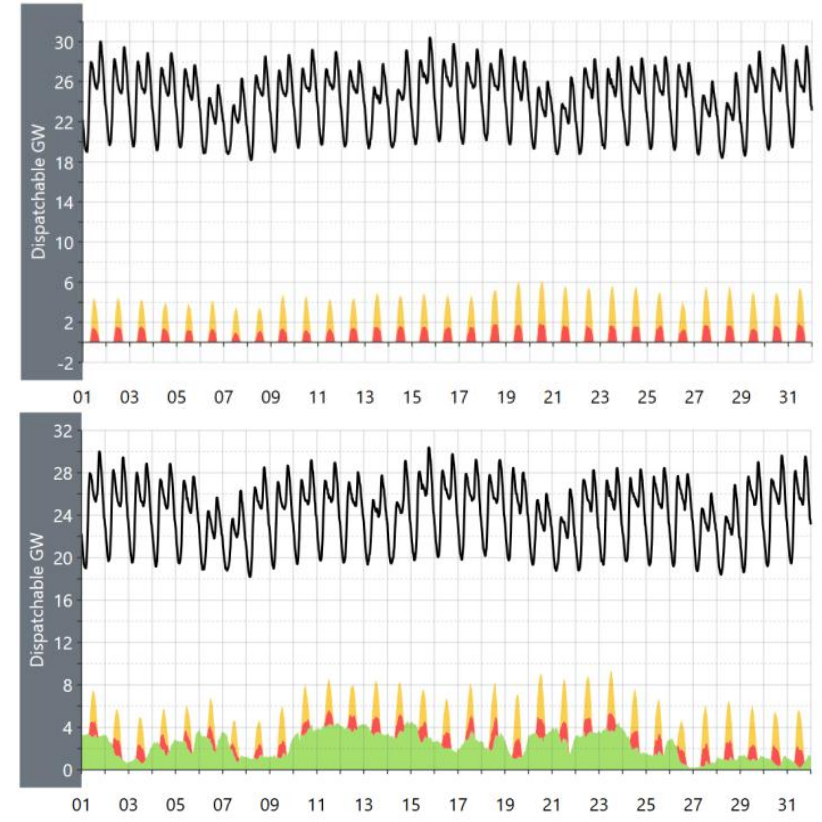

Fig. 3- Total NEM grid demand, and wind and solar facilities and solar rooftop power supply over one sample month, July 2019, that is a mid-winter month in Australia. Images reproduced modified from [9]. Top to bottom, grid total, wind, solar and rooftop solar, and wind plus solar and rooftop solar.
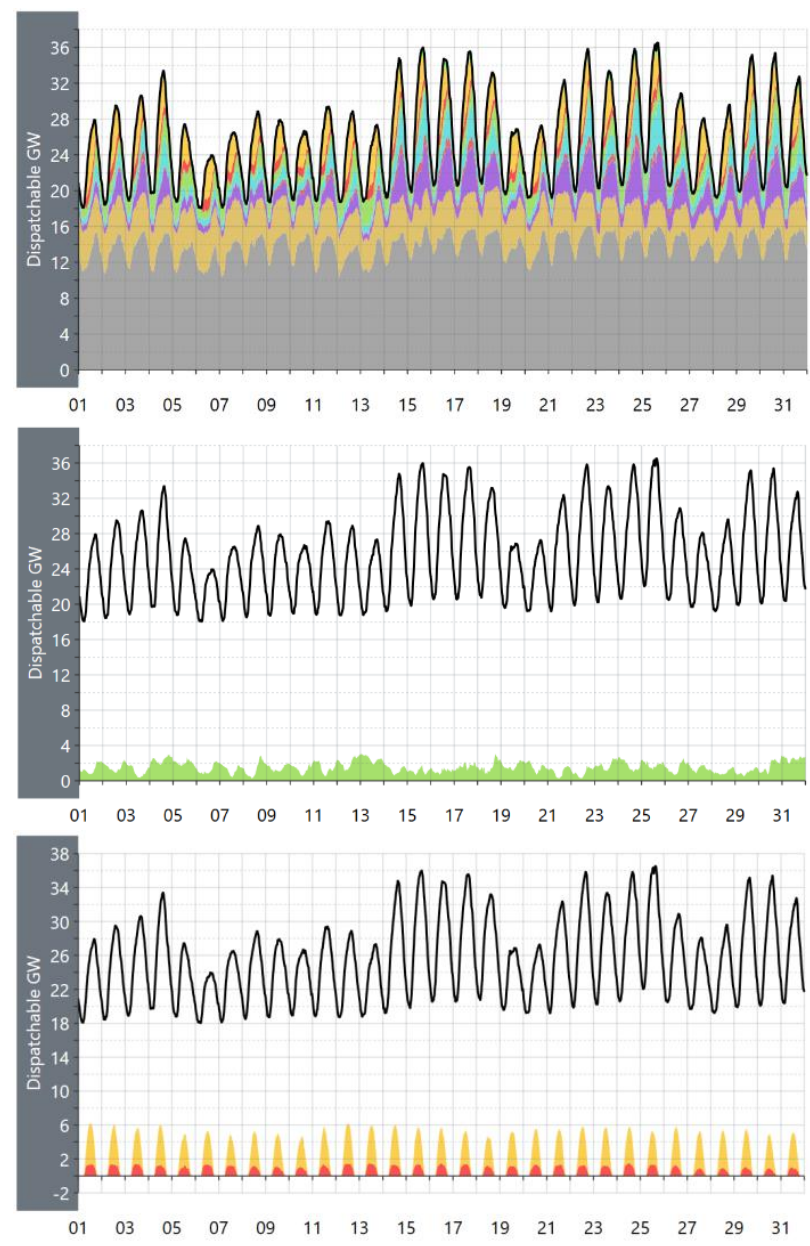

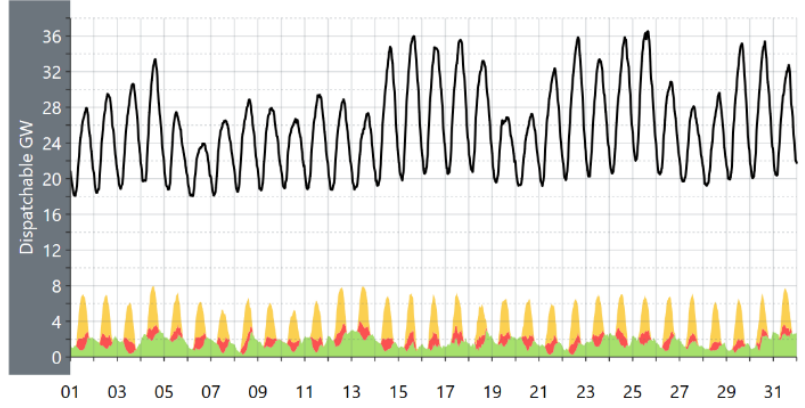

Fig. 4. Total NEM grid demand, and wind and solar facilities and solar rooftop power supply over one sample month, January 2019, that is a mid-summer month in Australia. Images reproduced modified from [9]. Top to bottom, grid total, wind, solar and rooftop solar, and wind plus solar and rooftop solar.

Especially nigh time, low wind conditions, are nightmares for grid stability. If we consider July 2019, Fig. 3, the 26 of July 2019, at 20:00 hours, the power demand from the grid was $24.4 \mathrm{GW}$, but the power from wind was only $0.2 \mathrm{GW}$. Solar and rooftop solar was obviously $0 \mathrm{GW}$ at that time. Not even 100 times the present nominal capacity could have prevented a blackout without other sources additional to the wind and without energy storage. Fig. 5 presents the total NEM grid demand, and wind and solar facilities and solar rooftop power supply over two sample days, one is July 26, 2019, and the other is January 3, 2019. During January 3, very low wind conditions occurred between 12:00 and 15:00 hours. So, the situation at 20:00 hours was dramatic, but not as dramatic as it was on the $26^{\text {th }}$ of July 2019.

The production of solar and wind also changes with the season. During the winter, solar energy production reduces, while it increases during the summer. The wind has a somewhat conflicting pattern, as the summer months are usually characterized by smaller wind energy production. If we consider January 2019, Fig. 4, the grid demand is sometimes up to $36 \mathrm{GW}$, while it is often up to 28 in Fig.3. Same time, wind energy production is similarly dramatically reduced, while solar energy production is similarly dramatically increased.

Regarding the energy storage requirements, these include not only the actual generating and storing power, but also the time energy can be released or stored at the actual, not nominal, generating or storing power. The requirements for battery energy storage are thus massive, for both nominal (registered) power and nominal capacity.

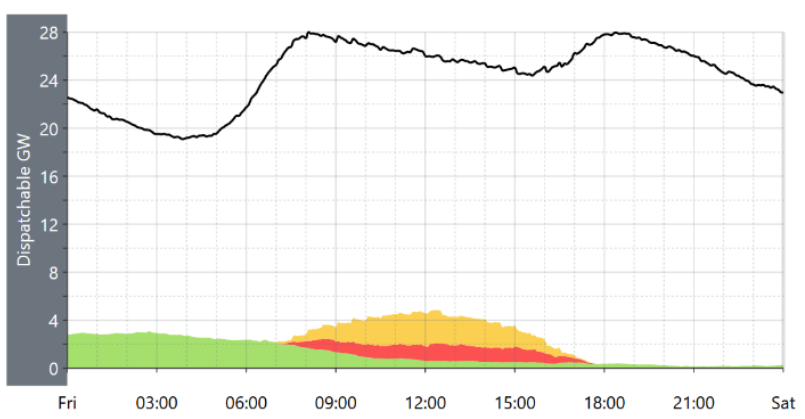




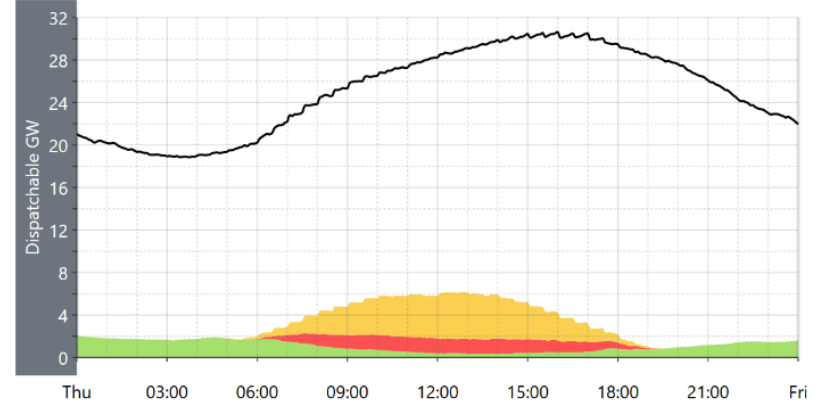

Fig. 5. Total NEM grid demand, and wind and solar facilities and solar rooftop power supply over two sample days, July 26, 2019, and January 3, 2019. Images reproduced modified from [9].

\section{Discussion and conclusions}

To have the Australian National Electricity Market electric grid wind and solar, that is non-sense with a total primary energy supply mostly by fossil fuels, energy storage is needed. Apart from the opportunity to convert existing hydropower stations to pumped hydro (PHES), that is a short term trick to sell twice the same hydropower, there are no other simple solutions. Saltwater pumped hydro is still in its infantry (the only small demonstration plant built so far has been already shut down). There are then only batteries to consider. Current technology Li-ion batteries are needed not only for our cell phones and computers, and for electric vehicles. These batteries are also needed to stabilize the energy production from wind and solar, to satisfy the requirements of a balanced grid. And these batteries are still far from what they should be.

As also discussed in [10], battery electric vehicles are non-sense without a total primary energy supply that is $100 \%$ renewable energy. This cannot happen until the energy storage issue is recognized and addressed, and huge capacities are built, not only of wind and solar but also of storage. Works such as [11] or [12], that is promoting electric mobility, as part of an electric economy, without having realized yet the obstacles, are misleading.

The Hornsdale world's largest battery by Tesla [13], [14] is only $100 \mathrm{MW}$ of nominal power, and $129 \mathrm{MW} \cdot \mathrm{h}$ of stored energy. However, it is working at maximum power in/out of only $30 \mathrm{MW}$ because of system stability, and it is similarly discharged at a fraction of the nominal full state of charge. What is needed worldwide as energy storage, for electric vehicles, for the grid, and every other electric TPES, is thus a very large number of batteries. The raw materials needed to produce the current technology Li-Ion batteries are difficult and expensive to be mined and unavailable in the quantities needed. There are environmental, sustainability, energetic and economic costs to build the Li-ion batteries needed by the wind and solar power station, by the electric vehicles, and whatever is electric, that is simply unaffordable.

If the battery energy storage needed is thus unaffordable, and similarly unaffordable is the wind and solar capacity for all of the total primary energy supply, alternative solutions must be sought. Hydrogen may be produced from excess wind and solar energy when there will be some. It may also be produced from natural gas and coal, with existing processes that only needs optimization. In this case, it would be better to use hydrogen vehicles than battery electric vehicles for transport. As battery energy storage is challenging for sustainability, economic and environmental issues, a significant hydrogen production should be considered [15], [16], [17], [18], [19], [20].

The perspectives of storage of wind and solar energy, and renewable hydrogen production, as well as the production of hydrogen from natural gas, and coal in Australia are further discussed and expanded in [21] and [22].

The authors received no funding and they have no conflict of interest to declare. The authors wish to thank Andrew Miskelly for the use of the images from his web site anero.id/.

\section{References}

1. IEA, IEA World Energy Balances. 2019. webstore.iea.org/world-energy-balances-2019

2. Boretti, A., Energy storage requirements to address wind energy variability, Energy Storage. 1(5), e77, 2019.

3. Boretti, A., Energy storage needs for an Australian National Electricity Market grid without combustion fuels, Energy Storage, 2019, DOI:10.1002/est2.92.

4. IRENA, Renewable Capacity Statistics, 2019. http://www.irena.org/-/media/Files/IRENA/Agency/ Publication/2019/Mar/RE_...

5. AEMO, Fact SheetThe NationalElectricity Market, 2018. www.aemo.com.au/-

/media/Files/Electricity/NEM/National-Electricity-

Market-Fact-Sheet.pdf

6. Parkinson, G., AEMO pushes solar register as rooftop installations head to $56 \mathrm{GW}, 2019$. reneweconomy.com.au/aemo-pushes-solar-register-asrooftop-installations-head-to-56gw-53869

7. Boretti, A., High-frequency standard deviation of the capacity factor of renewable energy facilities - part 1 : solar photovoltaic, Energy Storage, 2019. DOI:10.1002/est2.101

8. Boretti, A., High-frequency standard deviation of the capacity factor of renewable energy facilities - part 2: wind, Energy Storage, 2019. DOI:10.1002/est2.100

9. Aneroid Energy, Energy Production by Source, 2019. anero.id/energy/

10. Boretti, A., Battery electric vehicles are non-sense without a total primary energy supply $100 \%$ renewable energy and this cannot happen until the energy storage issue is recognized and addressed, 2019. science.sciencemag.org/content/366/6464/422/tab-eletters

11. Crabtree, G., The coming electric vehicle transformation, Science, vol. 366, pp. 422-424, 2019.

12. International Energy Agency, Global EV Outlook, 2019. www.iea.org/publications/reports/globalevoutlook2019/

13. Spector, J., The Biggest Batteries Coming Soon to a Grid Near You, 2019. www.greentechmedia.com/articles/read/the-biggestbatteries-coming-soon-to-a-grid-near-you

14. hornsdalepowerreserve, The Hornsdale Power Reserve, 2019, hornsdalepowerreserve.com.au/

15. Crabtree, G.W., Dresselhaus, M.S. and Buchanan, M.V., The hydrogen economy. Physics Today, 57(12), pp.39-44, 2004. 
16. Barreto, L., Makihira, A. and Riahi, K., The hydrogen economy in the 21 st century: a sustainable development scenario. International Journal of Hydrogen Energy, 28(3), pp.267-284, 2003.

17. Clean Energy Council, Clean hydrogen could power Australia's next export boom, 2019. www.cleanenergycouncil.org.au/news/clean-hydrogencould-power-australias-next-export-boom

18. Mazengarb, M., Renewable hydrogen getting cheaper, Australia could lead global market, 2019. reneweconomy.com.au/renewable-hydrogen-gettingcheaper-australia-could-lead-global-market-95168/

19. Gronewold, N., Momentum Builds for Hydrogen Fuel in Japan, Australia, 2019. www.scientificamerican.com/article/momentum-buildsfor-hydrogen-fuel-in-japan-australia/

20. Deign, J., How Australia Is Looking to Develop a Hydrogen Economy, 2019. www.greentechmedia.com/articles/read/how-australia-islooking-to-develop-a-hydrogen-economy

21. Al-Kouz, W., Boretti, A., and Nayfeh, J., Perspectives of storage of wind and solar energy, and renewable and coal hydrogen production in Australia, 2019. Preprint

22. Boretti, A., Perspectives of production of hydrogen for export from wind and solar energy, natural gas, and coal in Australia, 2019. Preprint. 